\title{
Use of complementary and alternative medicine before and after organ removal due to urologic cancer
}

\author{
Jens Mani' \\ Eva Juengel' \\ Ilhan Arslan' \\ Georg Bartsch' \\ Natalie Filmann ${ }^{2}$ \\ Hanns Ackermann ${ }^{2}$ \\ Karen Nelson ${ }^{3}$ \\ Axel Haferkamp' \\ Tobias Engl ${ }^{1, *}$ \\ Roman A Blaheta ${ }^{1, *}$ \\ 'Department of Urology, ${ }^{2}$ Institute \\ of Biostatistics and Mathematical \\ Modeling, ${ }^{3}$ Department of Vascular \\ and Endovascular Surgery, Johann \\ Wolfgang Goethe-University, \\ Frankfurt am Main, Germany \\ *These authors contributed equally to \\ this work
}

Correspondence: Jens Mani

Department of Urology, Goethe-

University, Theodor-Stern-Kai 7,

D-60590 Frankfurt am Main, Germany

Tel +49696301 7109

Fax +4969 630I 7108

Email jens.mani@kgu.de
This article was published in the following Dove Press journal:

Patient Preference and Adherence

I October 2015

Number of times this article has been viewed

Objective: Many patients use complementary and alternative medicine (CAM) as primary treatment or symptom relief for a variety of illnesses. This study was designed to investigate the influence of surgical removal of a tumor-bearing urogenital organ on CAM use.

Methods: From 2007 to 2011, 350 patients underwent major urological surgery for kidney, prostate, or bladder cancer at the Goethe-University Hospital, Frankfurt, Germany. Data from 172 patients $(49 \%)$, who returned a questionnaire, were retrospectively evaluated using the hospital information system along with the questionnaire to objectify CAM use 2 years before and after surgery.

Results: From the 172 patients returning questionnaires, 56 (33\%) used CAM before and/or after surgery and 116 (67\%) never used CAM. Of the 56 CAM users, 30 (54\%) used CAM presurgery and 53 (95\%) used CAM postsurgery, indicating a significant change of mind about CAM use. Patients of German nationality used CAM significantly more than patients of other nationalities. Higher educational status (high-school diploma or higher) was a significant factor in favor of CAM use. The most common type of CAM used before/after surgery was an alternative medical system (63/49\%), a manipulative and body-based method (50/19\%), and a biologicalbased therapy (37/32\%). Information about CAM, either provided by medical professionals or by other sources, was the main reason determining whether patients used CAM or not.

Conclusion: The number of patients using CAM almost doubled after surgical removal of a cancer-bearing organ. Better awareness and understanding of CAM use by medical professionals could improve patient counseling.

Keywords: complementary and alternative medicine, surgery, urologic cancer

\section{Introduction}

Complementary and alternative medicine (CAM) encompasses a broad therapeutic area, not generally available at most allopathic medical centers. Currently, there is no established definition of CAM. The World Health Organization notes that the terms "complementary medicine" and "alternative medicine" tend to be interchanged with the term traditional medicine, but generally refer to "a broad set of health care practices that are not part of that country's own tradition and are not integrated into the dominant health care system". ${ }^{1}$ The National Center of Complementary and Alternative Medicine (NCCAM), a division of the National Institutes of Health in the United States, defines complementary medicine as being separate from alternative medicine. According to NCCAM, "complementary generally refers to using a non-mainstream approach together with conventional medicine" and "alternative refers to using a non-mainstream approach in place of conventional medicine". ${ }^{2}$ The inclusive term that NCCAM has adopted is "complementary health approaches", 
divided into two subgroups: natural products such as herbal remedies and mind and body practices such as meditation and massage. ${ }^{2}$

Despite lack of rigorous scientific evidence, a large proportion of the population uses CAM for a wide range of conditions and diseases, both as treatment, as well as for alleviating symptoms. Lack of definition and differences in survey instruments contribute to the difficulties in determining the actual prevalence of CAM use. Previous studies have linked CAM use to sex, ${ }^{3,4}$ age, ${ }^{5}$ educational status, ${ }^{3,6}$ income, ${ }^{6}$ disease status, ${ }^{7}$ and marital status. ${ }^{8}$ In industrialized countries, approximately $60 \%$ of the population reports at least one use of CA over a 12 -month period. ${ }^{9}$ Oncology patients appear to be among the highest users of CAM. ${ }^{10}$ In Europe, Australia, and North America, the prevalence of CAM use, together with or in place of conventional therapy, has been estimated to be approximately $50 \%$ in cancer patients, ${ }^{10-13}$ with up to $80 \%$ prevalence in the United States. ${ }^{14}$ In prostate cancer patients, $30 \%$ have been reported to use CAM. ${ }^{15}$ Dissatisfaction with conventional treatment and reduction of side effects related to chemotherapy are the most commonly given reasons to use CAM. ${ }^{16,17}$

In this retrospective, questionnaire-based survey, CAM use was examined in patients who underwent major urological cancer surgery with removal of kidney, bladder, or prostate gland. The primary objective of the study was to determine the prevalence of CAM use before and after surgery and whether the surgical procedure changed the patient's attitude toward CAM.

\section{Materials and methods}

From 2007 to 2011, a total of 350 patients underwent major urologic surgery for kidney, prostate, or bladder cancer in the Department of Urology at the Goethe University Medical Center in Frankfurt am Main, Germany (102: radical prostatectomy, 76: radical cystectomy, and 172: nephrectomy).

Patient data, including age, sex, body mass index (BMI), tumor type and stage, and timing of operation, were retrospectively collated using the hospital information system Orbis (Agfa Healthcare, Mortsel, Belgium). In addition, patients, 2-6 years after surgery, were sent a questionnaire by post, with 27 questions to objectify CAM use in the 2 years before and in the 2 years after surgery. The investigation was approved by the local ethics committee of the Goethe University Frankfurt, Main, Germany (project SUG-012015). Information about the study purpose was conveyed by letter, and written consent was obtained to use anonymous data for research purposes. Patients were motivated to contact the investigator about any queries concerning the study by phone or e-mail. No financial compensation for study participation was offered.

One section of the questionnaire contained questions about nationality, education, marital status, children, how patient learned about CAM, use of CAM within 2 years before and 2 years after surgery, how long CAM was used, reason for use of CAM, use of a minimum of one type of CAM, or use of multiple types of CAM.

Another section of the questionnaire subjectively graded the CAM effect from 0 (no effect) to 10 (strong effect). The effect concerned quality of life, physical health, general health perception, and vitality. The type of CAM used by the patient was assigned to one of the five major CAM domains defined by NCCAM. ${ }^{2}$

1) Alternative medical system (homeopathic medicine and naturopathic medicine, traditional Chinese medicine, and Ayurveda)

2) Mind-body intervention (support groups, cognitivebehavioral therapy, meditation, prayer, mental healing, and therapies employing creative outlets such as art, music, or dance)

3) Biologically based therapy (natural substances such as herbs, foods, or vitamins)

4) Manipulative and body-based method (chiropractic or osteopathic manipulation and massage)

5) Energy therapy (biofield therapies such as qi gong, Reiki, and therapeutic touch and bioelectromagnetic-based therapy involving the unconventional use of an electromagnetic field).

Four groups were defined to conduct a statistical analysis to determine whether the surgical procedure changed the patient's attitude toward CAM:

1) CAM users before and after surgery

2) CAM users before surgery, but not after

3) CAM users after surgery, but not before

4) CAM nonusers before and after surgery.

Statistical analysis was performed using the statistical programs, BiAS 10:04 and SPSS. The Wilcoxon-Mann-Whitney test (nonparametric equivalent of the two-sample $t$-test), chi-square test (to examine differences with dichotomous variables), and chi-square contingency table (two-way table for analysis of categorical data) were used for statistical correlation analysis. $P<0.05$ indicates significant difference.

\section{Results}

Of the 350 postal questionnaires sent, 172 (49\%) were returned and included in the final analysis. Sociodemographic 
information about the survey participants is listed in Table 1. The study population had a mean age of 68 years and included 138 males and 34 females. The most common surgery in women was nephrectomy $(\mathrm{n}=25)$, and in males, prostatectomy $(n=62)$, followed by nephrectomy $(n=50)$. The majority

Table I Sociodemographics at surgery

\begin{tabular}{|c|c|c|}
\hline Demographic & $\begin{array}{l}\text { CAM users (pre-l } \\
\text { postsurgery), } n=56^{a, b}\end{array}$ & $\begin{array}{l}\text { Never used } \\
\text { CAM, } n=116\end{array}$ \\
\hline \multicolumn{3}{|l|}{ Age (years) } \\
\hline $31-40$ & $4(7 \%)$ & 0 \\
\hline $4 I-50$ & $9(17 \%)$ & $3(3 \%)$ \\
\hline $5 I-60$ & $15(27 \%)$ & $26(22 \%)$ \\
\hline $6 I-70$ & $21(38 \%)$ & $52(45 \%)$ \\
\hline $7 I-80$ & $7(11 \%)$ & $35(30 \%)$ \\
\hline \multicolumn{3}{|l|}{ Sex } \\
\hline Male & 47 (84\%) & 91 (78\%) \\
\hline Female & $9(16 \%)$ & $25(22 \%)$ \\
\hline \multicolumn{3}{|l|}{ Marital status } \\
\hline Single & $5(9 \%)$ & $7(6 \%)$ \\
\hline Married/partner & $41(73 \%)$ & $64(55 \%)$ \\
\hline Divorced & $8(14 \%)$ & $8(7 \%)$ \\
\hline Widowed & $2(4 \%)$ & $3(3 \%)$ \\
\hline Unknown ${ }^{c}$ & $N / A$ & $34(29 \%)$ \\
\hline \multicolumn{3}{|l|}{ Children } \\
\hline Yes & $4 \mathrm{l}(73 \%)$ & 68 (59\%) \\
\hline No & 15 (27\%) & $13(11 \%)$ \\
\hline Unknownc & $\mathrm{N} / \mathrm{A}$ & $35(20 \%)$ \\
\hline \multicolumn{3}{|l|}{ Education } \\
\hline No graduation from school & 0 & $13(11 \%)$ \\
\hline Secondary/modern school & $8(14 \%)$ & $24(21 \%)$ \\
\hline Secondary school & $13(23 \%)$ & 17 (I5\%) \\
\hline High school degree & $10(18 \%)$ & $7(6 \%)$ \\
\hline University degree & 25 (45\%) & $21(18 \%)$ \\
\hline Unknown ${ }^{c}$ & $\mathrm{~N} / \mathrm{A}$ & $34(29 \%)$ \\
\hline \multicolumn{3}{|l|}{ Gross income } \\
\hline$€ 30,000$ & 7 (13\%) & $19(17 \%)$ \\
\hline$€ 30,000-€ 60,000$ & $19(34 \%)$ & $25(21 \%)$ \\
\hline$€ 60,000-€ 100,000$ & $12(21 \%)$ & $19(17 \%)$ \\
\hline$>€ 100,000$ & $4(7 \%)$ & $6(5 \%)$ \\
\hline Unknownc & $14(25 \%)$ & $47(40 \%)$ \\
\hline \multicolumn{3}{|l|}{ Nationality } \\
\hline German & 52 (93\%) & 64 (55\%) \\
\hline Other & $4(7 \%)$ & $18(16 \%)$ \\
\hline Unknown ${ }^{c}$ & N/A & $34(29 \%)$ \\
\hline \multicolumn{3}{|l|}{$B M I^{d}$} \\
\hline$<20$ & 0 & $4(3 \%)$ \\
\hline $20-25$ & 18 (32\%) & 37 (32\%) \\
\hline $26-30$ & $23(41 \%)$ & $51(44 \%)$ \\
\hline $31-40$ & 15 (27\%) & $24(21 \%)$ \\
\hline \multicolumn{3}{|l|}{ Type of surgery } \\
\hline Nephrectomy & 27 (48\%) & 48 (4I\%) \\
\hline Prostatectomy ${ }^{\mathrm{e}}$ & $16(29 \%)$ & 45 (39\%) \\
\hline Cystectomy & $13(23 \%)$ & $23(20 \%)$ \\
\hline
\end{tabular}

Notes: ${ }^{n} \mathrm{n}=30$ (54\%) used CAM presurgery and $\mathrm{n}=53$ (95\%) used CAM postsurgery. ${ }^{b}$ All values in the table are expressed as number of participants (\%). 'Participant did not answer questions. ${ }^{\circ}$ Calculated from participant data at time of surgery. ${ }^{~}$ Percent based on number of males.

Abbreviations: CAM, complementary and alternative medicine; BMl, body mass index; N/A, not applicable. of survey participants ( $n=116,67 \%)$ did not use CAM either before or after surgery, and most of these individuals $(75 \%)$ were 61 years of age or older. The remaining 56 individuals were CAM users, 30 (54\%) of whom used CAM before surgery. After surgery, 53 (95\%) patients reported CAM use. Approximately 51\% of CAM users were 31-60 years of age and $49 \%$ were $61-80$ years (Table 1 ). There was no significant influence of age at surgery in the CAM users compared to the group not using CAM $(P=0.70)$.

Participants who used CAM before surgery obtained information about alternative medicine in approximately equal parts from their own research (eg, internet, (medical) journals, newspapers, and books), social environment (eg, family, friends, and peer), and from health professionals (eg, doctors, nurses, and alternative practitioners; Table 2). Nearly $90 \%$ of these individuals used CAM before surgery for constitution-related reasons, primarily to promote general health and to strengthen the immune system (Table 2). The three patients who used tumor-related CAM were patients with bladder cancer diagnosed early on through transurethral resection.

After surgery, more than $50 \%$ of CAM information originated from medical professionals (eg, doctor, nurse, and alternative practitioner; Table 2), and reasons for use were approximately equally split among the following categories: constitution, tumor, and therapy (Table 2). The most common type of CAM used before surgery was an alternative medical system (63\%), primarily including acupuncture and homeopathy and/or a manipulative and body-based method (50\%; Table 3). After surgery, an alternative medical system was the primary CAM use (49\%), followed by a biological-based therapy (32\%), which included therapeutic diet and phytotherapy (Table 3 ).

Table 2 Reasons for CAM use before and after surgery ${ }^{\mathrm{a}}$

\begin{tabular}{lll}
\hline & $\begin{array}{l}\text { Before surgery } \\
(\mathbf{n}=\mathbf{3 0})^{\mathbf{b}}\end{array}$ & $\begin{array}{l}\text { After surgery } \\
(\mathbf{n}=\mathbf{5 3})^{\mathbf{b}}\end{array}$ \\
\hline $\begin{array}{l}\text { Learned about CAM } \\
\text { Medical/health professionals }\end{array}$ & $17(57 \%)$ & $28(53 \%)$ \\
$\begin{array}{l}\text { Own initiative/own research } \\
\text { Lay information/social }\end{array}$ & $16(53 \%)$ & $21(40 \%)$ \\
environment & $15(50 \%)$ & $1 \mathrm{I}(2 \mathrm{1} \%)$ \\
Reason for CAM use & & \\
$\begin{array}{l}\text { Constitution related } \\
\text { Symptom based }\end{array}$ & $26(87 \%)$ & $19(36 \%)$ \\
Therapy based & $1 \mathrm{I}(37 \%)$ & $14(26 \%)$ \\
Tumor related & $9(30 \%)$ & $17(32 \%)$ \\
Other reasons & $3(10 \%)$ & $17(32 \%)$ \\
\hline
\end{tabular}

Notes: aParticipants may be included in more than one category. ${ }^{\mathrm{b}} \mathrm{All}$ values in the table are expressed as number of participants (\%).

Abbreviation: CAM, complementary and alternative medicine. 
Table 3 Types of CAM use before and after surgery ${ }^{\mathrm{a}}$

\begin{tabular}{lll}
\hline Type & $\begin{array}{l}\text { Before surgery } \\
(\mathbf{n = 3 0 )}\end{array}$ & $\begin{array}{l}\text { After surgery } \\
(\mathbf{n = 5 3})^{\mathbf{b}}\end{array}$ \\
\hline $\begin{array}{l}\text { Alternative medical system } \\
\text { Manipulative and body-based }\end{array}$ & $19(63 \%)$ & $26(49 \%)$ \\
method & $15(50 \%)$ & $10(19 \%)$ \\
$\begin{array}{l}\text { Biological-based therapy } \\
\text { Energy therapy }\end{array}$ & II (37\%) & $17(32 \%)$ \\
Mind/body intervention & $\mathrm{I}(3 \%)$ & $5(9 \%)$ \\
\hline
\end{tabular}

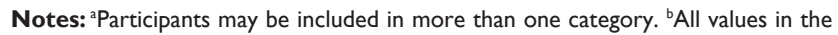
table are expressed as number of participants (\%).

Abbreviation: CAM, complementary and alternative medicine.

Only two participants (one before surgery and one after surgery) used the mind/body intervention of meditation (Table 3). More than half of the CAM users felt that CAM provided an overall improvement in their quality of life, general health, and emotional well-being.

The 56 patients who used CAM were distributed as follows: CAM users before and after surgery $(\mathrm{n}=27,16 \%)$, CAM users before surgery, but not after ( $n=3,2 \%)$, and CAM users after surgery but not before $(n=26,15 \%)$. Kidney cancer patients were more prone to continue with CAM treatment after surgery $(\mathrm{n}=18,67 \%)$ than prostate cancer patients $(\mathrm{n}=5$, $31 \%)$ or bladder cancer patients $(\mathrm{n}=4,30 \%)$.

Of the 116 non-CAM users, about one-third did not use CAM because their physicians did not recommend or provide information about it, while another $25 \%$ expressed no interest in alternative medicine (Table 4).

More patients of German nationality $(\mathrm{n}=54,93 \%)$ used CAM, whereas only a minority of other nationalities did so $(\mathrm{n}=4,7 \% ; P=0.036)$. A high-school diploma or higher educational status was a significant positive factor for CAM use $(P=0.011)$. All other factors, sex $(P=0.5212)$, BMI ( $P=0.36664)$, income $(P=0.597)$, marital status $(P=0.8737)$, or children $(P=0.1880)$, had no influence on CAM use.

The majority of patients who used CAM ( $\mathrm{n}=48,86 \%)$ as well as those not using CAM ( $\mathrm{n}=85,73 \%$ ) would welcome hospital guidance after surgery regarding CAM. CAM users would appreciate in-hospital CAM treatment options. Most CAM users report that CAM makes them feel safer $(n=50$,

Table 4 Primary reason for not using CAM

\begin{tabular}{ll}
\hline Reason & $\begin{array}{l}\text { Number of participants (\%), } \\
\mathbf{n}=116\end{array}$ \\
\hline Physician did not provide information & $36(31 \%)$ \\
No interest in alternative medicine & $29(25 \%)$ \\
No knowledge about CAM & $21(18 \%)$ \\
Bad experience with previous CAM & $2(2 \%)$ \\
No answer & $28(24 \%)$ \\
\hline
\end{tabular}

Abbreviation: CAM, complementary and alternative medicine.
$89 \%)$ and that they experience an improved quality of life $(\mathrm{n}=50,89 \%)$ through CAM use.

\section{Discussion}

Medical treatment in Germany is predominantly evidence based. Nevertheless, chronically ill patients and especially cancer patients are increasingly using CAM in industrialized nations despite the lack of evidence-based data concerning effectivity..$^{10}$ Germany is no exception.

In this investigation, the following CAM use by patients was documented: prostate cancer (29\%), renal cell carcinoma (48\%), and bladder cancer (23\%). Another investigation reports that $52 \%$ of patients with newly diagnosed prostate cancer use $\mathrm{CAM}^{18}$ and $40 \%$ of patients with advanced, palliatively treated prostate cancer use CAM. ${ }^{19}$ Higher reports of CAM use for breast cancer $(57 \%)^{20}$ and thyroid cancer $(74 \%)^{21}$ are documented.

Until now, the effect of organ removal on CAM use in the course of a urologic tumor operation has not been investigated. Taylor et $\mathrm{al}^{22}$ have described the emotional impact of colorectal cancer surgery with anxiety connected to the uncertainty of when and/or whether the cancer might return. Anxiety led to the desire for a more reliable body, with the hope that heightened monitoring and body management might increase reliability. Provided patients know about the potential health benefits offered by CAM, the desire for more reliability can be fostered and implemented. ${ }^{23}$ This investigation shows that many patients who did not use CAM before surgery used CAM after surgery. Most patients who used CAM before surgery maintained CAM use after surgery.

Different CAM modalities are employed according to the demographic, clinical, and behavioral situation, ${ }^{23,24}$ but Olchowska-Kotala ${ }^{25}$ could not explain why so many cancer patients were inclined to use CAM. In this investigation, organ removal was common to all patients, whereas other surveys encompassed widespread cancer treatment. Disappointment with regard to CAM would be expected when a tumor must be surgically removed during CAM use, but it appears that it only results in a shift in the type of CAM employed. The most commonly used CAM before surgery was an alternative medical system (63\%), manipulative and body-based methods (50\%), and biological-based therapies (37\%), often combined. After surgery, an alternative medical system remained most popular (49\%), with biological-based therapy (32\%) second in popularity and a manipulative and body-based method (19\%) third.

Studies have shown CAM use is related to sex, ${ }^{3,4}$ age, ${ }^{5}$ educational status, ${ }^{3,6}$ income, ${ }^{6}$ disease status, ${ }^{7}$ and marital status. ${ }^{8}$ 
In this investigation, there was no significant correlation between CAM use and sex, disease status, age, income, marital status, number of children, or BMI. There was a significant correlation between country of origin and education. With the migrant worker culture, less welleducated families have come to Germany, and although they might have been exposed to alternative medicine in their home country, ${ }^{26}$ costs associated with employing accustomed CAM may be prohibitive. ${ }^{27,28} \mathrm{CAM}$ is therefore not easily accessible to these families and requires explicit recommendation by the treating physician. , $^{610,27,28}$

Tumor type and T-, N-, and M-stage had no impact on CAM use in this investigation. Other studies have shown correlations to tumor stage and grading. ${ }^{20,29,30}$ The discrepancy may be due to study design since the patients in this investigation were evaluated before diagnosis and surgery. Other studies generally begin after more accurate diagnosis and thus more CAM use is reported, especially with high tumor staging. ${ }^{20,29}$ The most common source of information in previous studies was from family members. ${ }^{29}$ In this investigation, doctors and naturopaths were the main source of information before and after the surgery. This may be because doctors are obtaining training in alternative medicine, ${ }^{31-34}$ especially in large cities where additional income can be acquired by selling CAM-related products or treatments. ${ }^{13}$

Studies have shown that $70 \%$ of patients do not discuss CAM use with the doctor managing their cancer. ${ }^{35}$ Patients predominantly rely on their own research through internet, $\mathrm{TV}$, radio, and/or magazines both before and after the surgery, whereby the quality of CAM information can be very low. ${ }^{36,37}$ The removal of a cancer-bearing organ is a major change in life. Both the diagnosis of cancer and the functional loss through surgery may lead to more body and health awareness. Despite high interest in CAM use, communication between patients and surgeons and follow-up physicians is lacking. Because of the internet information flood, it is important for physicians to develop communication skills in this area, not only with patients, but with colleagues to avoid conflicting advice as to the use of CAM.

\section{Conclusion}

The number of patients using CAM almost doubled after surgical removal of a cancer-bearing organ. Medical professionals influence whether patients use CAM, and since CAM can offer health, social, and economic benefits, professional guidance in CAM use would be in the patients' best interests.

\section{Perspective}

The use of CAM is on the rise, especially in the Western world where patients are increasingly demanding holistic disease treatment. Since professional guidance is often lacking, patients often try managing their own CAM application. More preclinical and clinical studies are necessary to identify CAM mechanisms of action so as to optimize combining the different CAM types with evidence-based medicine.

\section{Author contributions}

JM, GB, EJ, AH, TE and RAB: study concept and design, acquisition of data; JM, HA, NF, IA, KN, TE and RAB: analysis and interpretation of data; JM, KN, IA and RAB: drafting the manuscript; GB, NF, HA, EJ, AH and TE: critical revision of the manuscript for important intellectual content; all authors read and approved the final manuscript.

\section{Disclosure}

The authors report no conflicts of interest in this work.

\section{References}

1. Zhang Q. Traditional medicine: definitions. Available from: http:// www.who.int/medicines/areas/traditional/definitions/en/. Accessed May 2015.

2. National Center for Complementary and Integrative Health. Complementary, alternative, or integrative health: what's in a name? Available from: http://nccam.nih.gov/health/whatiscam\#term. Accessed May 2015.

3. Jordan ML, Delunas LR. Quality of life and patterns of nontraditional therapy use by patients with cancer. Oncol Nurs Forum. 2001;28: 1107-1113.

4. Kappauf H, Leykauf-Ammon D, Bruntsch U, et al. Use of and attitudes held towards unconventional medicine by patients in a department of internal medicine/oncology and haematology. Support Care Cancer. 2000; 8:314-322.

5. Paltiel O, Avitzour M, Peretz T, et al. Determinants of the use of complementary therapies by patients with cancer. J Clin Oncol. 2001; 19:2439-2448.

6. Boon H, Brown J, Gavin A. What are the experiences of women with breast cancer as they decide whether to use complementary/alternative medicine? West J Med. 2000;173:139.

7. Sollner W, Maislinger S, DeVries A, Steixner E, Rumpold G, Lukas P. Use of complementary and alternative medicine by cancer patients is not associated with perceived distress or poor compliance with standard treatment but with active coping behavior: a survey. Cancer. 2000;89: 873-880.

8. Pedersen CG, Christensen S, Jensen AB, Zachariae R. Prevalence, socio-demographic and clinical predictors of post-diagnostic utilisation of different types of complementary and alternative medicine (CAM) in a nationwide cohort of Danish women treated for primary breast cancer. Eur J Cancer. 2009;45:3172-3181.

9. Leach MJ. Profile of the complementary and alternative medicine workforce across Australia, New Zealand, Canada, United States and United Kingdom. Complement Ther Med. 2013;21:364-378.

10. Shneerson C, Taskila T, Gale N, Greenfield S, Chen YF. The effect of complementary and alternative medicine on the quality of life of cancer survivors: a systematic review and meta-analyses. Complement Ther Med. 2013;21:417-429. 
11. Cramer H, Cohen L, Dobos G, Witt CM. Integrative oncology: best of both worlds-theoretical, practical, and research issues. Evid Based Complement Alternat Med. 2013;2013:383142.

12. Horneber M, Bueschel G, Dennert G, Less D, Ritter E, Zwahlen M. How many cancer patients use complementary and alternative medicine: a systematic review and metaanalysis. Integr Cancer Ther. 2012;11: 187-203.

13. Huebner J, Micke O, Muecke R, et al. User rate of complementary and alternative medicine (CAM) of patients visiting a counseling facility for CAM of a German comprehensive cancer center. Anticancer Res. 2014;34:943-948.

14. Saghatchian M, Bihan C, Chenailler C, Mazouni C, Dauchy S, Delaloge S. Exploring frontiers: use of complementary and alternative medicine among patients with early-stage breast cancer. Breast. 2014; 23:279-285

15. Bishop FL, Rea A, Lewith H, et al. Complementary medicine use by men with prostate cancer: a systematic review of prevalence studies. Prostate Cancer Prostatic Dis. 2011;14:1-13.

16. Citrin DL, Bloom DL, Grutsch JF, Mortensen SJ, Lis CG. Beliefs and perceptions of women with newly diagnosed breast cancer who refused conventional treatment in favor of alternative therapies. Oncologist. 2012;17:607-612.

17. Gillett J, Ientile C, Hiscock J, Plank A, Martin JM. Complementary and alternative medicine use in radiotherapy: what are patients using? J Altern Complement Med. 2012;18:1014-1020.

18. Beebe-Dimmer JL, Wood DP Jr, Gruber SB, et al. Use of complementary and alternative medicine in men with family history of prostate cancer: a pilot study. Urology. 2004;63:282-287.

19. Paul M, Davey B, Senf B, et al. Patients with advanced cancer and their usage of complementary and alternative medicine. J Cancer Res Clin Oncol. 2013;139:1515-1522.

20. Kang E, Yang EJ, Kim SM, et al. Complementary and alternative medicine use and assessment of quality of life in Korean breast cancer patients: a descriptive study. Support Care Cancer. 2012;20:461-473.

21. Rosen JE, Gardiner P, Saper RB, et al. Complementary and alternative medicine use among patients with thyroid cancer. Thyroid. 2013;23: 1238-1246.

22. Taylor C, Richardson A, Cowley S. Surviving cancer treatment: an investigation of the experience of fear about, and monitoring for, recurrence in patients following treatment for colorectal cancer. Eur J Oncol Nurs. 2011;15:243-249.

23. O'Connor EL, White KM. Intentions and willingness to use complementary and alternative medicines: what potential patients believe about CAMs. Complement Ther Clin Pract. 2009;15:136-140.
24. Buettner C, Kroenke CH, Phillips RS, Davis RB, Eisenberg DM, Holmes MD. Correlates of use of different types of complementary and alternative medicine by breast cancer survivors in the nurses' health study. Breast Cancer Res Treat. 2006;100:219-227.

25. Olchowska-Kotala A. Individual differences in cancer patients' willingness to use complementary and alternative medicine. Adv Clin Exp Med. 2013;22:855-860.

26. Nuwaha F, Musinguzi G. Use of alternative medicine for hypertension in Buikwe and Mukono districts of Uganda: a cross sectional study. BMC Complement Altern Med. 2013;13:301.

27. Cui Y, Hargreaves MK, Shu XO, et al. Prevalence and correlates of complementary and alternative medicine services use in low-income African Americans and whites: a report from the Southern Community Cohort Study. J Altern Complement Med. 2012;18:844-849.

28. Misra R, Balagopal P, Klatt M, Geraghty M. Complementary and alternative medicine use among Asian Indians in the United States: a national study. J Altern Complement Med. 2010;16:843-852.

29. Chan JM, Elkin EP, Silva SJ, Broering JM, Latini DM, Carroll PR. Total and specific complementary and alternative medicine use in a large cohort of men with prostate cancer. Urology. 2005;66:1223-1228.

30. Micke O, Bruns F, Kurowski R, et al. Predictive value of carbohydrate antigen 19-9 in pancreatic cancer treated with radiochemotherapy. Int J Radiat Oncol Biol Phys. 2003;57:90-97.

31. Chung HJ, Kim M, Bae JS. Complementary and alternative medicine in patients with breast cancer. J Breast Cancer. 2006;9:361-366.

32. Joos S, Musselmann B, Miksch A, Rosemann T, Szecsenyi J. The role of complementary and alternative medicine (CAM) in Germany a focus group study of GPs. BMC Health Serv Res. 2008;8:127.

33. Joos S, Musselmann B, Szecsenyi J. Integration of complementary and alternative medicine into family practices in Germany: results of a national survey. Evid Based Complement Alternat Med. 2011;2011:495813.

34. Tabali M, Ostermann T, Jeschke E, Witt CM, Matthes H. Adverse drug reactions for CAM and conventional drugs detected in a network of physicians certified to prescribe CAM drugs. J Manag Care Pharm. 2012;18:427-438.

35. Roberts CS, Baker F, Hann D, et al. Patient-physician communication regarding use of complementary therapies during cancer treatment. J Psychosoc Oncol. 2005;23:35-60.

36. Brauer JA, El Sehamy A, Metz JM, Mao JJ. Complementary and alternative medicine and supportive care at leading cancer centers: a systematic analysis of websites. J Altern Complement Med. 2010;16:183-186.

37. Matthews SC, Camacho A, Mills PJ, Dimsdale JE. The internet for medical information about cancer: help or hindrance? Psychosomatics. 2003;44:100-103
Patient Preference and Adherence

\section{Publish your work in this journal}

Patient Preference and Adherence is an international, peer-reviewed, open access journal that focuses on the growing importance of patient preference and adherence throughout the therapeutic continuum. Patient satisfaction, acceptability, quality of life, compliance, persistence and their role in developing new therapeutic modalities and compounds to optimize

\section{Dovepress}

clinical outcomes for existing disease states are major areas of interest for the journal. This journal has been accepted for indexing on PubMed Central The manuscript management system is completely online and includes a very quick and fair peer-review system, which is all easy to use. Visit http://www dovepress.com/testimonials.php to read real quotes from published authors. 